\title{
Fenomenologia e resistência em Levinas
}

\section{Phenomenology and Resistance in Levinas}

DOI: 10.12957/ek.2020.48559

Dndo. Klinger Scoralick

scoralickk@yahoo.com.br

Pontifícia Universidade Católica do Rio de Janeiro

\section{RESUMO}

Os apontamentos feitos por Levinas, em especial em suas primeiras obras, voltam-se para análises fenomenológicas de elementos que evidenciam uma posição de hesitação ou de resistência em relação à ontologia $\mathrm{e}$ ao horizonte sem saída que nela se inscreve. De modo adverso, Levinas lança uma interrogação que acompanhará todo o seu percurso filosófico e que atinge o coração da filosofia: tudo é conação de ser? A crítica se endereça para uma fatalidade inscrita no estar aí abandonado às possibilidades do ser - estar atado à própria existência -, ou seja, à condição de esquiva impossível das fronteiras que o ser demarca. De tal modo, tem-se que a inamovibilidade, oriunda da presença do ser, interrompe a mobilidade dos entes. A proposta de Levinas indica que em meio ao ser há uma luxação ou uma necessidade de evasão em relação a si mesmo, um recuo. Pode-se notar, já em seus primeiros escritos, um aceno não apenas para a questão da ética como filosofia primeira, mas, também, para a questão sobre o político, que se delineia sob traços de um não, isto é, resistência.

\begin{abstract}
The notes made by Levinas, specially in his first works, focus on phenomenological analyses of elements that show a position of hesitation or resistance in relation to the ontology and the dead-end horizon that is inscribed in it. In an adverse way, Levinas provokes a questioning that will go alongside his entire philosophical journey and that reaches the heart of philosophy: is everything a conation of being? Critic moves towards a fatality that is inscribed in a position of abandonment to the possibilities of the being - be tied to its own existence - that is, to the condition of the impossible escape from the frontiers defined by the being. In such a way, it is considered that the irremovability, originating from the presence of the being, interrupts the mobility of the entities. Levinas' proposal indicates, concerning the being, that there is a dislocation or a need to escape from oneself; a retreat. Since his first writings, it is perceivable a nod not only to the matter of ethics as primal philosophy, but also to the matter about politics, which is delineated under the features of a no, that is, resistance.
\end{abstract}

Palavras-chave: Levinas. Fenomenologia. Resistência. Não-ter-que-ser.

Keywords: Levinas. Phenomenology. Resistance. Not having to be. 
A capacidade humana de cavar-se uma toca, de criar uma casca, de erguer ao redor de si uma tênue barreira defensiva, ainda que em circunstâncias aparentemente desesperadas, é espantosa e mereceria um estudo profundo. (LEVI, 1988, p. 79$80)$.

A primazia do mesmo ou da identidade é comentada em Totalidade e infinito como o ensinamento que Sócrates nos legou: "Nada receber de Outrem a não ser o que está em mim, como se, desde toda a eternidade, eu já possuísse o que me vem de fora." (LEVINAS, 1974, pp. 13-14). Em Levinas, o caminho da crítica dirigida ao sufocamento ontológico (totalidade), isto é, a contestação desobediente da determinação do outro pelo mesmo, que decorre do fato de que há o ser e de que todas as coisas são e se preservam sendo, inicia-se em seu texto intitulado Da evasão, de 1935. Em uma menção tácita e ao mesmo tempo explícita a Heidegger - referência que se faz marcante em toda a obra filosófica própria do autor - a ótica em questão interpela a relação do homem com o ser (Das Sein) e a coloca sob juízo. O eu está aprisionado ao ser e à necessidade de ter-queser? Haveria como se esquivar à gesta de ser, à determinação espessa produzida pelo real na qual encontra-se o eu aí lançado? Levinas aponta para a possibilidade uma perspectiva que desvencilha aquilo que se mostra ao existente, ao eu, desde seu fundamento, como ter-que-ser-si-mesmo.

O ser (tò ón) que na tradição filosófica do Ocidente foi definido como essência ou substância, substrato, princípio ontológico, lógico e epistemológico de todos os seres, torna-se inteligível através da categoria de suficiência, ou mesmo, de satisfação. Nada falta. Procede-se, por conseguinte, a afirmação da identidade que atravessa sua inteligibilidade: o ser é o mesmo. O que se desdobra desde esse princípio torna a existência um absoluto, em que a consciência de si vem a ser, sincronicamente, consciência de tudo. A pressuposta suficiência, jamais superada, uniformiza e imobiliza as frequências do coração da filosofia a um só ritmo temporal e impõe-se como preocupação em ser, problema do ser enquanto ser. De modo programático, Levinas persegue a tarefa de renovar este austero problema sob "o risco de inverter certas noções que ao senso comum e à sabedoria das nações parecem as mais evidentes.” (LEVINAS, 1982, p. 127). Teria o fundamento do ser puro a universalidade outorgada por Aristóteles? Encontra-se a questão de preocupação derradeira do humano no âmbito do ser? (Ibid., p. 
99). O eu recolhe-se na coincidência dos opostos? A filosofia jamais, verdadeiramente, se voltou contra o ser e seus propósitos e acabou por confundir a sabedoria pungente, que emana da ontologia, com aquilo que se efetiva como o mais próprio e substancial em seu discurso e seu vigor juvenil, evitando arriscar-se no tracejo de uma significação para além do caráter absoluto que a evidência do primado fundamental da ontologia comporta. $\mathrm{O}$ confronto ao ontologismo, quando se deu, restringiu-se, tão-só, a uma linha de demarcação da transcendência e ao estabelecimento de seu elo com o ser finito ou do desacordo entre liberdade e ser, preservando a noção de suficiência do ser, o repousar do ser sobre si mesmo, que implica a velha lógica da identidade absorvendo e neutralizando a subjetividade e a alteridade em um ponto de fixação chamado totalidade. Em última instância, seu esforço foi uma disputa em prol de "um ser melhor, para uma harmonia entre nós e mundo ou para o aperfeiçoamento de nosso ser próprio.” (LEVINAS, 1982, p. 93). Dentro desse cenário, a transcendência configura-se como aquilo que está às voltas com o horizonte de compreensão (Verstehen), cerne de toda a filosofia heideggeriana (Cf. LEVINAS, 1974, pp. 53-76). Ao mesmo tempo, a questão da subjetividade torna-se um problema, afinal a insuficiência da condição humana não se regula pela suficiência do ser. Como ficará aqui exposto, a evasão é o indício desta insuficiência em que "o ser não aparece somente como obstáculo que o pensamento livre teria que transpor, nem como a rigidez que, convidando à rotina, exige um esforço de originalidade, mas como um aprisionamento do qual se trata de sair." (LEVINAS, 1982, p. 98). Levinas procura discorrer sobre a significação profunda do ser finito, não por meio da indicação da transcendência de seus limites, mas da denúncia do seu caráter absoluto e definitivo, em que a necessidade, ao invés de denotar gozo de si, ideal de perfeição e de comunhão com o ser, não mais anuncia o fim da condição de privação. Esse acontecimento cumpre-se na existência humana, na identidade do eu, uma vez que nela reside a possibilidade de fuga, de esvaecimento da tautologia circunscrita no ser. É um equívoco afirmar que a insuficiência da condição humana se origina de uma limitação do ser ou de sua ausência. A falta de ser não marca uma deficiência. Contrariamente, o problema reside em seu excesso, em sua plenitude.

O significado da noção de evasão é descrito por Levinas como uma necessidade aguda que rompe com os modelos da satisfação. Trata-se de uma empreitada para se livrar, escapar do sofrimento que se impõe ao eu, o qual é inerente à condição da 
identidade do ser, na medida em que conserva a imposição de que existir é estar referido a si, atado a si-mesmo (rivé à soi-même), sem qualquer recuo possível, sob a austeridade e a força do ser. "Esse fato é o próprio sofrimento, o 'sem saída' do contato.” (LEVINAS, 1974, p. 215).

\begin{abstract}
O conteúdo do sofrimento se confunde com a impossibilidade de se desamarrar do sofrimento. [...] Ele é o fato de ser diretamente exposto ao ser. Ele é feito de impossibilidade de fugir e recuar. Toda a agudez do sofrimento está nesta impossibilidade de recuo. (LEVINAS, 1979, p. 55)
\end{abstract}

O absurdo original do ser equivale a sustentar o peso do seu próprio ser. Há, para Levinas, um aspecto dramático, de brutalidade, que se encerra na experiência do ser, e que pode, também, ser melhor compreendido nas linhas iniciais do prefácio de Totalidade e infinito, onde Levinas afirma "que o ser se revela como guerra ao pensamento filosófico; [...] a guerra se produz como a experiência pura do ser puro." E conclui: "A prova de força é a prova do real.” (LEVINAS, 1974, p. IX). Segundo Levinas, o limiar do trágico consiste na preservação da identidade, na sentença imposta ao sujeito: ser si-mesmo, sujeito ao ser e submetido a sua irremissibilidade. A posição que o eu ocupa em meio a essa ambiência é um enclausuramento à presença do ser, presença ao eu, de modo que a afirmativa o ser é confirma o que está no sujeito, seu lugar, sua identidade. Diante de tal situação-limite, que expressa o significado do ser puro e sua condição insuportável nãohá-mais-nada-a-fazer. O que liga o eu de modo primordial ao ser impõe-se como uma situação de fim do mundo e, simultaneamente, como urgência de saída. É justamente "na situação de fim do mundo [que] se põe a relação primeira que nos liga ao ser." (LEVINAS, 1998, p. 26). Diante do fim do mundo, ou em meio a ele, submerso, a busca por um refúgio, já anunciada em Algumas reflexões sobre a filosofia do hitlerismo, tornase o cerne da narrativa do autor em 1935. Os escritos dos anos 1930 possuem essa marca fenomenológica, decorrente, em parte, da gravidade dos desdobramentos políticos na Europa. Em Da evasão o sujeito é retratado, constitutivamente, por uma oposição a si mesmo, não à maneira de um embate entre o eu e o não-eu, mas, sim, por uma imagem de rasgo interior (déchirement), que paralisa a convicção de que se está atrelado ao ser “como a juventude à flor" (LEVINAS, 1982, p. 109). Contra a atestação ordenada de que existir é estar referido a si surge uma acusação que firma uma necessidade de evasão enquanto acontecimento indispensável para o sujeito. A evasão é decorrente da presença 
do ser, do sofrimento que dele se origina. Equivale a evasão a uma premência de excendência (excendance), elemento constitutivo da subjetividade, "necessidade de sair de si-mesmo, isto é, de quebrar o encadeamento mais radical, o mais irremissível, o fato de que o eu é si-mesmo." (LEVINAS, 1982, p. 98). Uma recusa à constância irrompe por dentro do próprio ser, um esforço de saída pulsa e torna-se aspiração que se direciona, ainda às cegas, ao atravessamento das fronteiras do ser e à ruptura do encadeamento do eu a si, expulsão de si. Contudo, esse impulso visceral de torção não garante o seu êxito. Não há saída no ser e a evasão não pode se realizar ou mesmo encontrar repouso. O prazer tampouco poderia ser considerado uma evasão, uma vez que a saída que ele proporciona conserva-se durante o intervalo de um instante, indicando um momento extático. O prazer surge como uma saída paliativa, uma forma de evasão enganosa, aventura que reassume uma posição originária quando se cessa o êxtase (LEVINAS, 1982, p. 110). Portanto, a existência humana encontra-se anunciada sob a condição de ser atada, acorrentada ao ser, incapaz de transpor as delimitações da identidade do ser, sem escapatória.

Dizer não à situação na qual o eu encontra-se atado/lançado, isto é, realizar uma saída da experiência do ser puro revela-se uma impossibilidade. O que se segue é que a incapacidade da evasão caracteriza a apropriação conceitual que Levinas faz do termo Geworfenheit (estar-lançado), traduzido em Martin Heidegger e a ontologia pela palavra derrelicção (déreliction) (LEVINAS, 1974, pp. 68-69). A interpretação de Levinas afirma a impossibilidade da transcendência em meio ao mundo, o que contesta o pensamento heideggeriano para o qual há uma transcendência implicada na abertura de uma possibilidade que pertence ao Dasein (Ser e tempo, §31) e que se cumpre na facticidade imposta a ele como projeto (Entwurf).

O Dasein, enquanto é, já se entendeu e continua se entendendo a partir de possibilidades. [...] O entender, como projetar, é o modo-de-ser do Dasein em que este é suas possibilidades como possibilidades. [Dasein verstehen sich immer schon und immer noch, solange es ist, aus Möglichkeiten. [...] Das Verstehen ist, als Entwerfen, die Seinsart des Daseins, in der es seine Möglichkeiten als Möglichkeiten ist.] (HEIDEGGER, 2012, p. 413).

Através do projetar-se — assumido sob a angústia do ser-para-a-morte — ressoam as possibilidades pertencentes ao Dasein, o seu poder-ser mais próprio, o seu ser entregue à responsabilidade de ser cada vez mais minheidade (Jemeinigkeit) — transcendência que se reassenta em sua própria verdade. Na contramão da proposta heideggeriana, que 
afirma uma transcendência na finitude, um lugar privilegiado para o ser humano composto por uma abertura de possibilidades existenciárias em sua facticidade, Levinas insiste no caráter negativo que emana dos limites do ser. Conforme Levinas, há uma fatalidade inscrita no estar aí abandonado às possibilidades do ser, na condição de se estar atado à própria existência, que se traduz por uma esquiva impossível das fronteiras que o ser demarca, de tal modo que a inamovibilidade oriunda da presença do ser interrompe a mobilidade dos entes. Afirma Rolland que "a reflexão de Levinas vai se deter sobre a Geworfenheit de modo a descobrir e a descrever uma situação onde a existência não encontra mais nela uma propensão indo além da situação imposta, [isto é] uma situação na qual o ser jogado paralisa, de certo modo, toda a possibilidade de se projetar." (ROLLAND, 1982, p. 28). A ubiquidade do ser que confirma e confina o eu à corporeidade, fechando-o perenemente sobre si mesmo, impossibilita qualquer transcendência. Descreve-se uma noção de trágico que ignora o drama da possibilidade da impossibilidade de toda outra possibilidade, isto é, da morte, e que repousa sobre a condição sem saída imposta pela fatalidade do ser. Precedendo a angústia e o sofrimento nela implicado, existe uma indeterminação essencial, elemental, pode-se dizer, um sentimento que se traduz por náusea — afetividade que se indispõe à compreensão — e que impede o projetar-se.

Rechaçando a convicção heideggeriana de que o estranhamento do homem em meio ao mundo é fruto do esquecimento do ser e da verdade que ele manifesta, Levinas aponta para o fato de que provém da própria presença obsedante do ser um tal estranhamento. $\mathrm{O}$ estranhamento faz referência ao anonimato do ser, à sua impessoalidade, o que é comentado por Levinas em Da existência ao existente, através da noção de há (il y a), termo correlato ao es gibt heideggeriano, mas que não possui a mesma significação de abundância e generosidade que este último. Ao contrário, o há é sinônimo do impessoal, como chove (il pleut) ou anoitece (il fait nuit) (Cf. LEVINAS, 1998, p. 93-105). Na linguagem bíblica, o há representa o silêncio e a escuridão noturna que antecedem a palavra e a luz. A subjetividade permanece inquieta, almejando se desatar desses contornos do ser, horror das trevas, da noite que nada pronuncia e é percebida pela criança como algo sem saída. Não se diz aí de uma angústia (do nada), mas de um temor pelo mal. A experiência do há carrega consigo um sofrimento, um medo de ser, condição de abandono, que se traduz como impossibilidade de escapar à fatalidade do ser. 
Com efeito, adverte Levinas desde Da evasão — o que também havia sido, à sua maneira, sugerido em Algumas reflexões sobre a filosofia do hitlerismo - que uma exigência aguda se apresenta perante ao eu como necessidade de saída do ser. Essa intuição fenomenológica será o fio condutor a ser desenvolvido nas obras posteriores de Levinas. Como se dá a saída ou o que isso significa ainda não encontra respostas em 1935. Evocação enigmática, Da evasão apenas esboça os primeiros passos de uma argumentação que se consolidará plenamente em 1974, através da descrição de uma subjetividade entendida como substituição e sensibilidade. A referida obra deixa assegurada, forçosamente, a condução de uma reflexão que implica em situar a subjetividade, a identidade do eu e a transcendência sob um discurso que não se reduz ao ser. O que se desenvolve a seguir mostra a necessidade de condução de uma reflexão sobre um instante que escapa à mordedura do tempo, à sua sincronia. Certo, não será em direção a uma ideia de eternidade que a evasão irá se cumprir. "A eternidade não é senão a acentuação ou a radicalização da fatalidade do ser atado a ele mesmo." (LEVINAS, 1982, pp. 122-123). Para tanto, será necessário apresentar uma noção de tempo que não se prende ao sincronismo afixado pela ontologia, de modo que não permaneçam aprisionados, a subjetividade e aquilo que afirma-a (alteridade), a um destino temporal, a uma ordem ontológica. O passo primeiro para a consolidação dessa trajetória consiste em marcar a posição do sujeito ou seu recuo diante do ser - resistência.

O trabalho de Levinas articula-se como uma crítica à filosofia de Heidegger ao denunciar a falsa noção de abundância e generosidade presente no âmbito do ser, referência ao es gibt. Em Da existência ao existente, texto de 1947, também se menciona um estranhamento em relação ao ser que é oriundo não de sua ausência, mas sim em função de seu caráter irremissível e inamovível, assim como de sua impessoalidade. A noção do há é o que descreve o aspecto impessoal que compõe o ser, determinação pelo nada, presença constrangedora da noite e do silêncio que a acompanha, fazendo calar o dia. O há é a significação do ser em geral, a pura existência que não se aferra a assumir uma forma pessoal (LEVINAS, 1998, pp. 93-94). Forma a-substantiva, das coisas que se dissolvem na noite, o há representa a invasão obscura de uma densidade do vazio, a despersonalização, o sufocamento, a presença inevitável de um silêncio e de um sem respostas - anonimato essencial. Diz Levinas que a aproximação do há é o horror, o que não é uma angústia diante da morte. "É de sua subjetividade, de seu poder de existência 
privada que o sujeito é despojado no horror. Ele é despersonalizado.” (LEVINAS, 1998, p. 100). Uma vez feito coisa entre as coisas, estando à mão do ser, sob sua serventia, o eu afoga-se no nada. Referência ao sem saída da existência o há inverte a subjetividade do sujeito, sua particularidade de existente, bloqueando qualquer recuo. Para explicar essa dimensão de anonimato e de impessoalidade que decorre do significado original da relação com o ser, verbalidade desprovida de substantivo, Levinas lança mão da descrição de uma existência sem mundo, situação que remete a um existir sem-si, estado anterior ao mundo. O há representa a escuridão da noite, a falta de referencial. Não se refere a isto, aquilo ou alguma coisa. Sob a ausência do substantivo, o há deixa indicada sua impessoalidade, indeterminação sinalizada pelo verbo sem o sujeito diante do desaparecimento de tudo. A impessoalidade que o há evoca faz com que as formas percam sua substância e sua especificação, tudo é o mesmo e o sujeito não encontra um lugar, antes despersonaliza-se ou, se preferir, é extinto. Presença da ausência, o há remete a um mundo que é dado à percepção através da vigília e não da consciência. Não se trata de um "retorno de alguma coisa, mas de uma presença; é o despertar do há no seio da negação — é uma infalibilidade do ser em que não se relaxa jamais a obra de ser; é sua própria insônia." (LEVINAS, 1998, p. 110). Conserva-se, pois, uma insônia, um estado que mantém uma vigília sem finalidade, sem sujeito e sem objetos. "A vigília é anônima. Não há minha vigilância à noite, na insônia: é a própria noite que vela. Vela-se [Ça veille].” (LEVINAS, 1998, p. 111). Regência de um pensamento anônimo, o há faz dissipar todos os personagens. Sem sono, sem descanso, solo ou posição o há é um pesadelo, esforço, obrigação ao ser. Somente por meio da posição de um sujeito se fará possível suspender a insônia, que atesta a própria eternidade do ser. O sujeito marca sua posição em meio ao ser, afirma-se ou surge, por uma retração ou distração. Os elementos, os estados de consciência que descrevem a hesitação que torna possível a subjetivação do sujeito revelam uma profundidade subjacente - caminho por dentro do ser que se traduz como preguiça, cansaço, sono. Levinas quer evidenciar o fato de que existe uma falta de firmeza diante do esforço. Não está o sujeito predestinado ao esforço. Desobedece-se às exigências do ser. Em meio ao ser há uma luxação em relação a si mesmo, um cansaço de ser. Dessa forma, é pela dinâmica do repouso, de modo geral, que se fortalece, em meio à existência, o surgimento de um existente, seu nascimento - que se dá por meio daquilo que evita a permanência, inscrição de uma passividade no âmago do ser. A isso 
chama-se hipóstase, subjetivação do sujeito, movimento de passagem do verbo ser ao substantivo em meio ao sem começo e sem fim do ser impessoal, movimento em direção à consciência. Resistindo a toda indeterminação do há, que despersonaliza ou desubstancializa o eu, a hipóstase promove um abandono do se é e inaugura o eu sou, maneira de ser.

\begin{abstract}
A hipóstase, a aparição do substantivo, não é somente a aparição de uma nova categoria gramatical; ela significa a suspensão do há anônimo, a aparição de um domínio privado, de um nome. Sobre o fundo do há surge um ente. A significação ontológica do ente na economia geral do ser — que Heidegger coloca simplesmente ao lado do ser por uma distinção encontra-se, assim, deduzida. (LEVINAS, 1998, p. 141)
\end{abstract}

Caracterizada como um refúgio, um recuo dentro da própria existência - abalo da suficiência do ser - o movimento hipostático abre espaço para uma vida interior (psiquismo), um acontecimento no ser, conforme irá afirmar Levinas na primeira seção de Totalidade e infinito (1961) e que também será denominado pelos termos separação ou ateísmo, resistência à totalidade. "Graças à dimensão da interioridade, o ser se recusa ao conceito e resiste à totalização.” (LEVINAS, 1974, p. 28). Nesses termos, o eu é um não, resistência. O "eu é sempre um Não em voz alta." [Ich ist stets ein laut gewordenes Nein.] (ROSENZWEIG, 2002, p. 193). Esse movimento de entificação - separação e resistência - resguarda o eu do jogo inscrito no ser através do estabelecimento de uma base, uma habitação. Vale ressaltar que a posição que aí se afirma, o aqui da consciência, não se refere ao Da (aí) do Dasein da analítica existencial de Heidegger. "O lugar, antes de ser um espaço geométrico, antes de ser um ambiente concreto do mundo heideggeriano é uma base." (LEVINAS, 1998, p. 122). O Da heideggeriano pressupõe o mundo e sua compreensão, todo horizonte e todo tempo. O aqui, por sua vez, precede a compreensão, ele "é o próprio fato de que a consciência é origem, de que ela parte de si mesma, de que ela é existente." (LEVINAS, 1998, p. 122). O sujeito assume um ponto de partida, de onde pode se desembaraçar e se assenhorar, desde uma base gerida por estados da consciência; ele não se põe, antes é a posição, irrupção: evento a significar que o corpo é o advento da consciência. Ou seja, o lugar não é uma coisa, mas corporeidade.

Levinas defende a ideia de que a consciência não é um cogito (penso) abstrato. Embora estenda a mão a Descartes, assumindo, à sua maneira, a definição da subjetividade como uma substância que pensa, isto é, pensamento que tem um ponto de 
partida em primeira pessoa, Levinas retrata a subjetividade como um acontecimento no ser em que sua posição se afirma no aqui de sua materialidade: o corpo. Portanto, a posição assumida pela hipóstase possui uma base material que é a corporeidade, sujeito encarnado. (Ética $e$ política somente podem ser pensadas a partir desta posição.) A noção de corporeidade possui importantes desdobramentos ao longo da obra de Levinas, pois é através dela que se poderá significar a relação de acolhimento diante do rosto, assim como anunciar a saída do ser por meio da categoria de sensibilidade ou vulnerabilidade. $\mathrm{O}$ fato de a corporeidade colocar sob condição o eu e a consciência torna possível a afirmação de uma filosofia que não se realiza sob os modos da abstração. "A localização da consciência não é subjetiva, mas é a subjetivação do sujeito.” (LEVINAS, 1998, p. 118). A interioridade - evasão em si e hipóstase — torna-se possível a partir da corporeidade, de modo que se afirma a ideia de um corpo psíquico e não de um psiquismo incorporado. O corpo é a própria instância da passagem da existência ao existente, que interrompe e reata a duração1; "a posição é o próprio acontecimento do instante como presente." (LEVINAS, 1998, p. 124). A subjetividade em Levinas é definida sob a consistência da corporeidade, o que torna a dimensão da sensibilidade requisito indispensável para o percurso que será proposto à subjetividade e que culminará no rompimento com as conexões do ser, sobretudo dentro daquilo que se apresenta em Outramente que ser ou mais além da essência (1974). O recuo à interioridade (habitação) apontado pelo autor, torna-se possível através do próprio corpo, o que faz indicar uma sustentação da subjetividade pela via da materialidade. Esta "oferece ao sujeito uma libertação em relação a si mesmo, no próprio instante da transcendência da necessidade, colocando-o em face dos alimentos, em face do mundo como alimento." (LEVINAS, 1979, p. 51).

\footnotetext{
1 Em entrevista concedida a Philippe Nemo, publicada sob o título de Ética e infinito, Levinas fala da importância e contribuição do pensamento de Bergson para se pensar uma filosofia diversa do ser, de uma espiritualidade do novo, "realidade própria e irredutível do tempo." Em Bergson o passado preserva-se de maneira vital, impulsionando o agir; e a duração prolonga esse passado de maneira criadora. O élan vital bergsoniano proporciona o surgimento de uma consciência que se abre ao novo. É através da categoria de duração que, segundo Levinas, surge um caminho de ruptura com o mecanicismo universal, privilégio concedido ao modelo científico de tempo.
} 
Contrariamente a Heidegger, Levinas entende que "antes de ser um sistema de utensílios, o mundo é um conjunto de alimentos.” (LEVINAS, 1979, p. 45). A vida interior é gozosa, é fruição. Essa situação de plenitude se dá, sobremaneira, na relação com os alimentos, em um eu satisfeito porque alimentado. A ética só é possível em um mundo sem fome. "A subjetividade toma sua origem na independência e na soberania do gozo.” (LEVINAS, 1974, p. 86). O gozo (jouissance), que se encontra na interioridade, coloca o sujeito inserido no âmbito da satisfação, de modo que toda a espiritualidade da terra se orienta ou deveria se orientar para o gesto de se alimentar, conforme menciona Levinas no Preâmbulo de Difícil liberdade (1963, p. 10). A in-condição da subjetividade, da qual fala Levinas no percurso de sua obra, está amparada em um ente que se alimenta, que está provido em suas necessidades e, portanto, é forte, tem consistência, substancialidade material. Assim sendo, a materialidade e suas implicações ou situações são fundamentais para que a hipóstase aconteça. "O mundo oferece ao sujeito a participação no existir sob forma de gozo e por conseguinte lhe permite existir à distância de si." (LEVINAS, 1979, p. 51-52). O sujeito nasce do evento de sua posição. Dá-se, então, o começo da significação no ser, em que o lugar (corpo) é uma condição, subjetivação da subjetividade. A análise sobre a hipóstase abre margens para o início daquilo que se apresentará no Prefácio de Totalidade e infinito como uma defesa da subjetividade outramente que ser. Na habitação, recuo na interioridade diante da presença do ser e de sua impessoalidade, é possível se esquivar de sua indiferenciação e de seu anonimato, que torna tudo o mesmo, obra da totalidade ou da semelhança. Esse recuo - "poder do recuo infinito" (LEVINAS, 1998, p. 77-78) - diante do ter-que-ser, do sentido que se arma no ser, não é algo da ordem da intencionalidade ou da compreensão, mas falência - lapso, fissão, distensão, fratura, torção, luxação, dor, envelhecimento, loucura, ferida, sonolência, preguiça, cansaço, atraso, não-memória, perseguição -, isto é, resistência-passividade-traumatismo, economia de um corpo que acolhe-padece e diz não. 


\section{Referências bibliográficas}

HEIDEGGER, Martin (1927). Ser e tempo. Trad. Fausto Castilho. São Paulo: Unicamp; Petrópolis: Vozes, 2012.

LEVI, Primo (1947). É isto um homem? Trad. Luigi Del Re. Rio de Janeiro: Rocco, 1988. LEVINAS, Emmanuel (1935). De l'évasion. Montepellier: Fata Morgana, 1982 (Le Livre de Poche).

LEVINAS, Emmanuel (1947). De l'existence a l'existant. Paris: Vrin, 1998.

LEVINAS, Emmanuel. Difficile liberté: essais sur le judaïsme. Paris: Albin Michel, 1963.

LEVINAS, Emmanuel (1949). En découvrant l'existence avec Husserl et Heidegger. Paris: Vrin, 1974.

LEVINAS, Emmanuel (1991). Entre nous: essai sur le penser-à-l'autre. Paris: Grasset \& Fasquelle, 1998 (Le Livre de Poche).

LEVINAS, Emmanuel (1982). Éthique et infini. Paris: Fayard, 1993.

LEVINAS, Emmanuel (1948). Le temps et l'autre. Montpellier: Fata Morgana, 1979.

LEVINAS, Emmanuel (1934). Quelques réflexions sur la philosophie de l'hitlérisme. Paris: Rivages, 1997.

LEVINAS, Emmanuel (1961). Totalité et infini: essai sur l'extériorité. La Haye: Martinus Nijhoff, 1974.

ROLLAND, Jacques. Sortir de l'être par une nouvelle voie. In: LEVINAS, Emmanuel (1935). De l'évasion. Montepellier: Fata Morgana, 1982 (Le Livre de Poche).

ROSENZWEIG, Franz (1921). Der Stern der Erlösung. Freiburg im Breisgau: Universitätsbibliothek, 2002.

Recebido em: 19/02/2020 | Aprovado em: 28/02/2020 